\title{
DE LO FÓRICO A LAS PERSPECTIVAS EN LA ENUNCIACIÓN. ANÁLISIS DE CONSTRUCCIONES PRESENTATIVAS DEFINIDAS EN ESPAÑOL
}

Adrián Pablo Fanjul

\begin{abstract}
RESUMEN
Este artículo trata sobre la ocurrencia, en español, del verbo "haber" con artículo definido, revisando algunas interpretaciones a la luz de teorizaciones sobre la enunciación que cuestionan la unicidad del sujeto hablante. La consideración de las perspectivas y voces en la enunciación conduce a focalizar un tipo específico dentro de las construcciones presentativas definidas, sobre el cual se informan búsquedas en corpora y conclusiones acerca de su potencial en el funcionamiento argumentativo.
\end{abstract}

PALABRAS-CLAVE: construções apresentacionais; perspectiva na enunciação; artigo definido.

\section{Introducción}

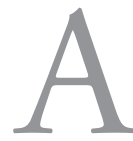

bordaremos en este texto la problemática de la ocurrencia, en español, del artículo definido como determinante de argumentos del verbo "haber" en construcciones presentativas existenciales. Intentaremos mostrar que el análisis de esas combinaciones requiere, sobre todo en los casos en los cuales el artículo no es la única ni la principal forma de determinación posible, considerar categorías de la configuración enunciativa y, por medio de ellas, el despliegue argumentativo del enunciado.

Nuestra explicación observará, entre esas construcciones presentativas, diversas configuraciones sintáctico-semánticas tipificadas en estudios descriptivos referidos a la lengua española. Irá focalizando un tipo en especial, carac- 
terizado por sustantivos relacionados con valores modales y un complemento introducido por "de", como en "Hay la sospecha de que pudiera utilizar recursos públicos ${ }^{1}$ ”, porque consideramos que es el que más claramente muestra la necesidad de tener en cuenta las perspectivas enunciativas y el funcionamiento dialógico-argumentativo que las mismas vehiculizan.

El artículo se divide en cinco secciones. En la primera, introducimos el problema de las restricciones para la determinación definida en construcciones presentativas y mostramos algunas explicaciones formuladas para el español. En la segunda, abordamos críticamente la extensa sistematización realizada recientemente en la versión integral, destinada a especialistas, de la Nueva gramática de la lengua española (RAE, 2009).

En la tercera sección, recurriremos a desarrollos de teorías de la enunciación acerca de las perspectivas personales y su relación con la conceptualización y representación de mundo en el enunciado, interrogando a partir de ellas las realizaciones de "haber" con diversos tipos de determinación. Cerramos esa misma sección sintetizando la interacción de los factores considerados en relación con el subtipo de construcción focalizada. En la cuarta parte, presentamos resultados de algunas búsquedas en corpora que pueden sustentar una hipótesis sobre la potencialidad argumentativa específica para esa construcción, que relacionamos con su presencia en determinados campos y géneros discursivos. La quinta sección corresponde a las conclusiones.

\section{Construcciones presentativas y determinación definida}

Las construcciones presentativas muestran, en diversas lenguas, fuertes restricciones para introducir sintagmas nominales definidos. Leonetti (1999b, p. 815) explica esa "restricción de definitud" por la difícil combinación entre, por una parte, determinantes que requieren un referente informativamente accesible y, por otra, un requisito para la función de "presentación": que en la interlocución no se haya introducido ya la presuposición de existencia de las entidades referidas. Leonetti se refiere en especial al verbo "haber" en español, pero señala que se advierten restricciones análogas en otras lenguas, sin que eso implique una propiedad "universal".

1 Uno de los casos encontrados en los corpora digitales para la lengua española a los que nos referiremos en la cuarta parte del artículo. 
En efecto, en español, la limitación es especialmente perceptible, dentro de los sintagmas nominales definidos, para el nombre propio, el pronombre personal nominativo y el posesivo. La literatura coincide en señalar como prácticamente informulables o "agramaticales" posibilidades como "*En la sala hay Jorge", "*Sólo había yo" o "*Sobre el estante hay mi ropa”, y las búsquedas en corpus arrojan resultados prácticamente nulos para ese tipo de combinaciones $^{2}$. En cambio, para el demostrativo y para el artículo definido se reconocen diversos contextos de ocurrencia con "haber" que, debido a la contradicción que evidencian en relación al carácter presentativo de ese verbo, y al efecto de extrañamiento que producen en el plano estilístico, han sido objeto de atención en diversos trabajos.

Los estudios siempre han presentado esas ocurrencias como "excepciones" que escapan a una restricción o a una regla. Más recientemente, los instrumentos de búsqueda en corpus han corroborado, dentro de su universo de alcance, la presunción de frecuencia relativamente baja para esas construcciones. En uno de los dos corpora electrónicos a los que nos referiremos en la cuarta sección de este artículo, el Corpus del Español, de Brigham Young University, encontramos que "haber" seguido por artículo definido arroja, para el siglo XX, 490 ocurrencias, y seguido por demostrativo, arroja 201, contra 7.546 seguido por articulo indefinido y 2815 por sustantivo sin determinante.

Una de las explicaciones producidas al respecto en la reflexión lingüística sobre el español es lo que Fernández Ramírez llama "mención evocativa" (1987, p. 132). Ocurre, para ese autor, cuando se busca que el interlocutor produzca la individualización del referente mediante un proceso que requiere "un llamamiento a la memoria" y que "apunta como deixis al concepto que va a formarse" (1987, p. 132). Algunos ejemplos que da el autor en la misma página son (numeración nuestra):

(1) Hay en el retrato de la niña esa redicha precisión de Don Vicente.

(2) Entre el ministro y el Infante hubo los roces y aún las violencias que pueden existir entre varones de genio no manso.

2 En los dos corpora que referiremos en la cuarta parte de este artículo hicimos búsquedas para combinaciones de "haber" con pronombres personales y con posesivos, indagando por categoría y por formas específicas, con resultados cero o prácticamente insignificantes. 
Por lo que tiene de ajuste entre las representaciones del locutor y del interlocutor, el concepto propuesto por Fernández Ramírez, que no se limita a casos con "haber", es asimilable a lo que Apothéloz (2003, pp. 69-71) explica como "deixis de la memoria", relacionándola, a su vez, con lo que otras tradiciones descriptivas han denominado como deixis "enfática" o "emotiva". Para la autora, el procedimiento está relacionado con un efecto de empatía, experimentado como acceso inmediato a las representaciones del locutor o del ser representado en el enunciado. Los ejemplos que da en francés no incluyen construcciones presentativas, pero la analogía con el problema que estamos examinando se da por la tensión entre una primera mención y el efecto de consabido.

Recientemente, una obra gramatical de porte publicada en lengua española realizó una amplia revisión explicativa sobre la ocurrencia de "haber" con artículo definido. A esa obra y a los interrogantes que suscita nos referimos en la sección siguiente.

\section{Propuestas en la nueva gramática de la lengua española}

En el año 2009 se publicó la obra en dos volúmenes denominada Nueva gramática de la lengua española (RAE, 2009), en adelante, NGLE. Promovida por la Real Academia Española y la Asociación de Academias de la Lengua Española, se trata de un instrumento que se reconoce a la vez como descriptivo y normativo. La obra, de más de 3.000 páginas, con un lenguaje y terminología dirigidos a especialistas, se muestra en sintonía con la investigación más reciente sobre diversos aspectos del funcionamiento de la lengua, echando mano, para cada uno de ellos, de fundamentación teórica pertinente aunque sin explicitar sus fuentes, rasgo que constituye su lugar de acercamiento a un discurso normativo. A pesar de esa singularidad, debido al impacto y difusión que la $N G L E$ ha alcanzado en el ámbito académico y en la formación de especialistas, resulta pertinente, creemos, su observación analítica y crítica en medios especializados como este, ya que se instala como interlocutor en el campo científico. En especial para el tema que nos ocupa, la ocurrencia de "haber" con artículo definido, la NGLE presenta una de las más amplias compilaciones de posibilidades que hayamos visto hasta hoy en un tratado descriptivo, por lo cual su consideración resulta ineludible. 
La NGLE trata sobre las ocurrencias del artículo definido con "haber" en el subcapítulo "Grupos nominales definidos e indefinidos en construcciones existenciales” (RAE, 2009, pp. 1114-1121). En su tercer apartado ya afirma que "haber" impersonal impone un carácter indefinido a su argumento "con las excepciones que se mencionarán a lo largo de esta sección” (p. 1115).

De modo general, tipifica las muchas excepciones en dos órdenes: el valor cuantificador y lo que va a denominar como el funcionamiento endofórico del artículo. Agrupa todas las variantes de aparición de artículo definido introduciendo el argumento de "haber" como expresiones particulares de uno de esos dos grandes tipos. Como mostraremos a lo largo de este artículo, creemos que, en las analogías para hacer caber los diferentes problemas en esos dos órdenes, se dejan de lado fundamentalmente aspectos que tienen que ver con las perspectivas personales en la enunciación y que se manifiestan incluso en rasgos formales diferenciadores que afectan las relaciones fóricas. Nuestro foco en este trabajo recaerá sobre lo que se clasifica como "endofórico", pero nos referiremos primero brevemente a las lecturas cuantificadoras.

Algunas expresiones de medida, principalmente partitivas, a pesar de construirse con artículo definido, son efectivamente cuantificadoras, por lo tanto, indefinidas: "Hay la mitad / la cuarta parte de candidatos que el año pasado". Tanto es así que pueden ser parafraseadas por expresiones numerales como "dos veces / cuatro veces menos candidatos", que no producirían ninguna extrañeza combinadas con "haber". También dentro de las secuencias cuantificadoras que pueden aparecer con ese verbo, la NGLE considera superlativos como "el/la menor" o "el/la más mínimo/-a", con ejemplos como (RAE, 2009, p. 1118, numeración y destacado nuestro):

(3) No hay el menor peligro de que alguien te sorprenda.

(4) No había el más minimo margen para el error.

La clara posibilidad de reemplazo del fragmento destacado por el indefinido "ninguno/-a" ("ningún peligro", "ningún margen”) evidencia que la presencia allí del artículo "el/la” no agrega definitud.

Sin embargo, inmediatamente la NGLE extiende la misma explicación a construcciones con adjetivos como "necesario", "suficiente" y otros (prefigurando una lista que sería imposible cerrar), en casos como "En ese cuaderno 
hay la información suficiente para que podáis prever los golpes que se están preparando" o "Al comienzo de esta legislatura no había el esfuerzo imprescindible entre las tres administraciones" (p. 1118). Pero ocurre que, a diferencia de las anteriores, esas combinaciones no son reemplazables por "ninguno/-a" ni por "alguno/-a". Tampoco se confirma algo que allí mismo afirma la NGLE: que esos adjetivos no podrían faltar o que el artículo aparece "en función de la naturaleza gramatical del adjetivo". En efecto, nada indica que sea agramatical una formulación como "En ese cuaderno hay la información para que podáis prever los golpes...". Y en todos los casos presentados el artículo podría omitirse - no así en los superlativos mostrados antes -, lo cual nos hace pensar que el mismo no aparece en función de la "naturaleza" de esos adjetivos. En suma, la lectura cuantificadora no parece suficiente para explicar la posibilidad del artículo definido en esas expresiones presentativas, y los efectos de sentido con los que se relaciona al combinarse con esos adjetivos parecen requerir explicaciones más relacionadas con la negociación de representaciones en la interlocución, como vimos en la sección anterior para los casos de deixis de memoria. Como en los casos que serán el centro de nuestra reflexión, una visión atenta a la enunciación y a las orientaciones argumentativas parece tener algo para aportar.

Todas las otras combinaciones en las que "haber" recibe un argumento con artículo definido se incluyen, para la $N G L E$, dentro de lo que caracteriza como "usos endofóricos del artículo" (RAE, 2009, p. 1119). Debido al particular empleo que se hace del término "endofórico", diferente de las tradiciones en las que el mismo generaliza anáfora y catáfora en oposición a “exofórico" (por ejemplo, HALLIDAY Y HASAN, [1976] 2013, pp. 31-36), es importante comenzar por aclarar a qué se refiere el mismo en esa obra y en otras de la reciente gramatología en español.

La $N G L E$ entiende que hay un uso endofórico del artículo definido cuando "es algún modificador o complemento interno al grupo nominal definido el que aporta la información necesaria para que este pueda usarse en su primera mención" (RAE, 2009, p. 1054). En los ejemplos dados por la NGLE, el complemento interno es principalmente la cláusula relativa especificativa (p. 1054, numeración nuestra):

(5) Y entonces Patricia le dio la carta que había estado escribiendo durante toda la mañana. 
Esa tipificación de "empleo endofórico del artículo" ya se registra en Leonetti (1999a y 1999b) en el espacio de los estudios gramaticales sobre español. En otros ámbitos, encontramos la caracterización de ese tipo de ocurrencia como "identifying relative clause" (LYONS, 1999, p. 164). Ese mismo autor incluye esos casos entre los usos "catafóricos" (LYONS, 1999, p. 8), categoría en la que también Neves (1999, p. 392) encuadra construcciones con esa forma. Kleiber (1983, pp. 97-98) ve en las ocurrencias de artículo definido con relativa especificativa como primera mención uno de los fundamentos para defender la presuposición existencial como rasgo principal de la pragmática del artículo definido, por lo cual se entiende que no lo incluya en un tipo de denominación "fórica".

Lo que más nos llama la atención en el tratamiento que da la NGLE al problema de "haber" con definidos es que amplía considerablemente lo que, en la misma obra y en otra literatura anterior para el espańol como la ya referida, se viene entendiendo como "usos endofóricos del artículo", reuniendo una heterogeneidad de tipos que, desde nuestro punto de vista, desdibuja importantes diferencias.

Por un lado, se incluyen construcciones con relativa especificativa análogas a las que se presentaron como ejemplos de "uso endofórico", esta vez como argumento de "haber" (RAE, 2009, p. 1120, numeración nuestra):

(6) No había la mala leche que hay ahora ${ }^{3}$.

(7) No hubo la expresión de alegría y los comentarios arrogantes que habitualmente acompañaban sus triunfos empresariales.

Pero también aparecen - incluso iniciando la secuencia de casos "endofóricos" - construcciones con el artículo definido seguido por "mismo", explicando que "permite presentar una persona o cosa en función de su identidad con la cantidad o la cualidad de alguna noción ya introducida" (RAE, 2009, p. 1119). Cabe notar que si la noción ya está "introducida", hay una clara diferencia con los casos de relativa especificativa, que permiten traer algo aún no introducido siquiera como noción.

3 En español, "mala leche" suele entenderse figurativamente como predisposición a perjudicar, mala intención. 
Aún así, esos dos grupos tienen algo en común: el artículo definido es casi irreemplazable por el indefinido o por la ausencia de artículo. En efecto, parecería poco probable el uso de "unas" en vez de "las" en el siguiente ejemplo (p. 1119, numeración nuestra), y casi imposible, en el mismo, la ausencia de artículo antes de "mismas":

(8) En los cristales del mostrador hay las mismas manchas y además manchas del tarro de goma de pegar las etiquetas.

Tampoco en los casos con relativas (ver 6 y 7 arriba) parece posible sustituir el definido por la ausencia de determinante, y el indefinido parece más posible cuanto más individualizable resulte el referente del sustantivo, siendo prácticamente imposible en (6) debido al carácter continuo (no contable) de "mala leche".

En cambio, en los otros contextos considerados por la $N G L E$, no parece haber ningún rasgo de los otros componentes del sintagma nominal que requiera el artículo definido.

Por una parte, se presentan construcciones con adjetivos como "habitual", "típico", "usual", "consabido", proponiendo que presentan entidades como "arquetípicas". Algunos ejemplos son (p. 1119, numeración nuestra):

(9) En sus palabras había el típico desprecio de quien no tolera la discrepancia.

(10) Hubo el lógico malestar, pero al final no pasó nada.

Nótese que, a diferencia de los casos con relativas especificativas, de los cuales proviene históricamente, como vimos, la denominación "endofórico" en la investigación gramatical en español, nada parece impedir el empleo de "un" en lugar de "el", e incluso la ausencia de determinante. Eso impone preguntarse por los efectos de sentido con que se relaciona la ocurrencia del definido, que requieren una interrogación sobre las perspectivas en la enunciación como la que desarrollaremos en la sección siguiente y que tiene más que ver con la argumentación polémica que con la (arque)tipicidad.

Por otra parte, más diferencias aun muestra la última variante propuesta como "endofórica" y que será nuestro centro de atención durante el resto de 
este trabajo. Al presentarla, se dice (RAE, 2009, p. 1121): “La interpretación endofórica del grupo nominal se obtiene también con los complementos oracionales de muchos sustantivos abstractos". Algunos de los ejemplos que da son (p. 1121, numeración nuestra):

(11) Aunque había la certeza de que tales finezas no habían de llegar jamás a su noticia.

(12) Hay la teoría de que los juntaron después de muertos.

(13) Hay la necesidad imperiosa de seguir haciendo, de seguir pudiendo.

(14) Hay el peligro de que Isabel note el cambio.

Esas construcciones presentan importantes diferencias con las que se vienen caracterizando como "endofóricas", fundamentalmente las de relativas especificativas y/o las de "mismo/-a/-s". En primer lugar, no hay el menor obstáculo para la ocurrencia del indefinido o de la ausencia de determinante (a lo sumo con un paso a plural cuando puede haber una interpretación contable, como en 12) en vez del definido. También, y relacionado con lo que acabamos de afirmar, el complemento, en todos los casos encabezado por "de", más que señalar una "mismidad" con lo representado por el sustantivo, agrega una característica nueva, lo desarrolla. Las construcciones "endofóricas" con relativas y con "mismo" pueden limitarse a indicar una repetición espejada, cuya expresión más clara es el caso (6), arriba. En estos casos, en cambio, hay siempre un componente nuevo, que puede percibirse como argumento si notamos que todas ellas son observables como virtuales resultados de nominalizaciones, con la consecuencias que eso tiene en cuanto a la detematización de un participante (agente, experimentante o en otros papeles): alguien cree firmemente algo o está seguro de ello (11), alguien teoriza o especula (12), alguien o varios necesitan algo (13), o temen o recelan por una posibilidad (14). Y, por último, percibimos que, más precisamente que "abstractos", esos sustantivos, y otros como "sospecha", "temor", "deseo", que funcionan en construcciones análogas, están relacionados con la modalidad.

A partir de esas observaciones pasamos a tratar, en la sección siguiente, sobre aportes que pueden realizarse, considerando perspectivas en la enunciación, para interpretar efectos de la presencia de artículo definido en esas construcciones. 


\section{Poniendo en juego las perspectivas}

En el camino de indagar, en las marcas de la enunciación, aspectos de la semántica de los enunciados, la teorización enunciativa fue cuestionando la unicidad del sujeto hablante y explorando los modos, más o menos formalizables, de ubicación de otras voces en el decir. Uno de los trabajos de Ducrot que fue dando lugar a la teoría polifónica de la enunciación estableció un diálogo con la teoría literaria, fundamentalmente con trabajos sobre narración, para adoptar la noción de "centro de perspectiva", "la persona desde cuyo punto de vista se presentan los acontecimientos" (DUCROT, [1982] 2001b, p. 268). Esa "persona", entendida como un ser discursivo, no empírico, puede no coincidir, en determinados puntos del texto oral o escrito, con el locutor, aquel que se marca como responsable por el enunciado. Esa adopción de la perspectiva diferenciando el concepto de "enunciador" del de "locutor" acompañó una concepción crecientemente argumentativa y dialógica del lenguaje en ese autor.

También en el contexto de la reflexión teórica sobre la enunciación, Zoppi-Fontana (2004, p. 61) propone que la noción de perspectiva recupera "um princípio muito presente na literatura: aquele de que por trás de toda voz tem-se sempre um olhar que a sustenta". Esa noción de "mirada", en la enunciación linguística, no consiste en la percepción visual estudiada, por ejemplo, en la plástica, sino en el "complexo processo de categorização/ conceptualização fundante do conhecimento" (ZOPPI-FONTANA, 2004, p. 61). Por eso, perspectiva y conocimiento están estrechamente relacionados en el estudio de la enunciación. El juego de voces y miradas distribuye la atribución de saberes sobre el mundo representado, que se expresa en términos como "omnisciencia", tan usuales en los estudios sobre narrativa.

Para comenzar a explicar cómo la consideración de las perspectivas enunciativas puede ayudar al estudio de los problemas que nos ocupan en este artículo, vamos a echar mano por un momento, nosotros también, de un texto literario, a partir del cual volveremos, en primer lugar, sobre los grupos nominales con relativa especificativa.

En el cuento "El cautivo", de Jorge Luis Borges, una de las más breves narraciones de ese escritor argentino, se cuenta que un nińo de la llanura es capturado durante un ataque de indios a una aldea de blancos, y se cría y 
crece entre los indios. Los blancos lo reencuentran ya de adulto y él parece no recordar nada de su pasado ni de su familia o su lengua. Pero al llegar a la casa paterna, sufre un repentino rapto de memoria:

De pronto bajó la cabeza, gritó, atravesó corriendo el zaguán y los dos largos patios y se metió en la cocina. Sin vacilar, hundió el brazo en la ennegrecida campana y sacó el cuchillito de mango de asta que había escondido allí, cuando chico. (BORGES, 2004, p. 166)

Es la primera mención del "cuchillito de mango de asta". Es también la única, ya que ese objeto no interesará por otro motivo en la historia narrada. Esa primera mención está construida con artículo definido al modo de lo que en la sección anterior vimos que algunos denominan "uso endofórico" y otros "catafórico", y es interesante preguntarnos por su efecto en contraposición con el indefinido "un".

Leyendo "sacó un cuchillito de mango de asta que había escondido allí, cuando chico", puestos en el lugar de alocutarios, la visión y conocimiento del objeto se inaugura en el mundo representado a la vez que para nosotros, $y$, en el desplazamiento al pasado propuesto por la relativa, esas dos miradas siguen siendo una. En cambio, en la expresión con artículo definido que efectivamente encontramos en el cuento, algo se hiende en ese camino. Se revela otro lugar de mirar y conocer, un centro de perspectiva diferente de nuestra coincidencia con la mirada del narrador, ya que hay algo que "se sabe" y que perdimos. Ese lugar puede ser caracterizado a partir de algunas reflexiones en la teorización enunciativa que pasamos a explicar.

Por un lado, podemos atribuirlo al nivel que Flinich propone como "observador", desdoblándolo del enunciador:

Si el sujeto de la enunciación señala la posición desde la cual un yo habla y dirige a otro su discurso, el sujeto de la observación designa la posición en la cual un sujeto se instala para ofrecer una perspectiva de lo enunciado. El deslinde de ambas posiciones - enunciador, observador - muestra que el enunciador delega la función de observador en otra instancia 
ubicada ya no en el nivel enunciativo sino en el nivel enuncivo. (FLINICH, 2012, p. 83)

El "nivel enuncivo" corresponde, en la propuesta que esa autora asume, al mundo representado en el enunciado. Creemos que ese deslinde explica la hendidura que percibimos en la lectura. Pero ¿qué es lo que garantiza que ese desdoblamiento tenga consecuencias sobre el lugar de lector-alocutario? Creemos que Zoppi-Fontana (2004) ofrece una óptima solución a partir de la diferenciación que realiza entre dos lugares y dos perspectivas para la tercera persona en el juego enunciativo. Esa investigadora propone diferenciar dos planos para la enunciación. Uno es el de las relaciones dialógicas en la interacción, que pone en juego las perspectivas del "yo", del "tú" y de un "él" interno, tema u objeto del discurso. Otro es el reflejo especular del anterior a partir de la "perspectiva extrapuesta" de una mirada observadora, también tercera persona. El lugar de la tercera persona es el que articula, en su desdoblamiento, los dos planos, que se distinguen por el modo de focalización:

Há focalizaçáo interna quando os enunciados se apresentam de qualquer uma das perspectivas no plano das relaçôes dialógicas na interação. Há focalização externa quando os enunciados se apresentam de uma perspectiva extraposta (fora) do plano da interação. A passagem de uma focalização interna para uma externa está dada pelo lugar do ele observador. (ZOPPIFONTANA, 2004, p. 62)

Creemos que el efecto con el que se relaciona el empleo del artículo definido en contextos como el que acabamos de analizar, en los que opera la contradicción entre primera mención y efecto de correferencia, involucra ese tipo de pasaje entre perspectivas y, sobre todo, su proyección sobre la perspectiva del interlocutor. El movimiento acerca al interlocutor a la mirada del observador externo, de "máximo saber", por eso su fuerza dialógica y argumentativa. Y ponderamos que esa fuerza se realza grandemente en construcciones de "haber" con definido, debido a que el carácter presentativo de "haber" potencia la contradicción mencionada precisamente por la baja frecuencia de esa combinación que, como explicamos en la segunda sección, produce especial extrańamiento. 
Entre las construcciones de "haber" con articulo definido, creemos que las que más se relacionan con esa fuerza argumentativa dada por la perspectiva extrapuesta son precisamente aquellas en las que el definido podría no aparecer. Y especialmente las últimas de las que nos ocupamos en el apartado anterior, con los ejemplos (11) a (14), que combinan nominalización con una marca de modalidad. Intentaremos considerar esos factores por separado, para evaluar después lo que resulta de su integración.

Para Flinich,

La modalidad realiza la comparación entre un mundo expresado y un mundo de referencia. [...] De aquí que la modalidad, en términos generales, pueda ser vista como una deixis epistémica. La distancia variable que puede mediar entre el mundo de referencia y el mundo expresado da lugar a las diversas modalidades, tales como posibilidad, evidencia, obligación, etc. (FLINICH, 2012, p. 102)

Creemos que efectivamente los tipos de modalidad mencionados instalan una diferencia entre mundos creados o representados. Y pensamos que la nominalización, combinada con la determinación definida, realiza una doble operación que afecta la contraposición de esos mundos y las perspectivas enunciativas desde las cuales se realiza.

Retomemos el ejemplo (13) y veamos posibles variantes no nominalizadas del mismo:

(13’) Necesitamos / Se necesita imperiosamente seguir haciendo, seguir pudiendo.

Como lo muestra la variación de posibilidades para la expresión verbal, a las que podríamos agregar "es (imperiosamente) necesario" o formas personales menos genéricas, la nominalización saca de foco al participante (en este caso, el que "necesita"). Particularmente en su realización presentativa con "haber", la nominalización trae el "otro" mundo como implantación local en "este". Entre corchetes intentamos representar ese anclaje: 
(13) [En esta situación / aquí] hay (la / una) necesidad imperiosa de seguir haciendo, seguir pudiendo.

Recordemos que, al atribuir a los enunciados modalidades deóntica, epistémica, necesitativa u otras, se considera que no deja de haber una modalización más incluyente, un "afirmo que...", como explica Flinich (2012, p. 105), "la modalidad básica de la declaración presupuesta en todo enunciado". Creemos que en nominalizaciones como la de (13) más arriba esa aserción ocupa la perspectiva del locutor, trasladando la perspectiva modalizadora al "observador". Ese proceso nos parece semejante a lo que Ducrot ([1981] 2001a, pp. 152-153) denomina "autoridad polifónica", un ser discursivo no coincidente con el locutor ni con el alocutario (un "tercero extrapuesto", en términos de Zoppi-Fontana) a quien se le atribuye una aserción mediante introductores como "parece ser que". Y cuando se suma a ello la determinación con artículo definido, una de las posibilidades que mostramos en el ejemplo, creemos que el lugar de participante que la nominalización dejó fuera de foco tiende a ocuparse por el acercamiento de la perspectiva del interlocutor a la del "tercero extrapuesto", lugar de saber y de mirada abarcadora.

Sostenemos, por lo tanto, que la combinación de esos factores - término modalizador, nominalización con forma presentativa y determinación definida - realza la fuerza argumentativa y se revela especialmente propicia para campos y géneros discursivos de propensión polémica. Las indagaciones en corpora que hemos realizado muestran, como veremos en la sección siguiente, que esa hipótesis puede abrir productivos caminos de investigación.

\section{Algunas observaciones en corpora}

El alcance de este trabajo, como surge de los objetivos planteados en la Introducción, es exponer los aspectos de un problema, revisar respuestas dadas y fundamentar la pertinencia de un nuevo abordaje a partir de un determinado referencial teórico y descriptivo. Por lo tanto, nuestro recurso a búsquedas de corpus cumple una función de apoyo a la reflexión presentada y pretende mostrar la productividad y viabilidad de investigar en el rumbo sintetizado al final del apartado anterior. Para esa continuidad será necesario formular hipótesis específicas, que creemos que se beneficiarán de esta exploración. 
Mostraremos algunos datos cuantitativos, que inclusive resumiremos en dos tablas para su mejor visualización, pero nos interesa enfatizar desde ya que es decisiva la observación analítica de los casos, que aquí también informaremos. Se trata de corpora cuya unidad de caso son los textos, y las categorías discursivas que clasifican textos son, en cualquier modelo, necesariamente inestables, entre otras cosas porque un mismo texto puede manifestar varias de ellas en su superficie. Por eso, damos crucial importancia a las observaciones cualitativas que haremos sobre las relaciones entre casos y sobre algunos en especialt', sin las cuales resultaría imposible llegar a conclusiones que puedan prever regularidades.

Los dos corpora de consulta on line en los que realizamos búsquedas son el Corpus del Español, desarrollado por el lingüista Mark Davies en la Brigham Young University in Provo, Utah (www.corpusdelespanol.org), y el Corpus de Referencia del Español Actual (CREA), promovido por la Real Academia Española (http://www.rae.es/recursos/banco-de-datos/crea). En el primero, la búsqueda se diferencia por siglos, del XIII al XX, y realizamos nuestra indagación siempre en el siglo XX. El CREA abarca exclusivamente de 1975 a 2004. En ambos hay clasificación de los textos por categorías que permiten ubicar de modo aproximado aquello que, siguiendo la taxonomía propuesta por Maingueneau (2008, pp. 16-17), podemos considerar como "tipos de discurso" según áreas de prácticas sociales como política, literatura, industria cultural, ciencia o educación, así como, en el caso del Corpus del Español, algunos géneros específicos.

Ya mencionamos, en la primera sección, búsquedas comparativas para la ocurrencia general de "haber" con diferentes tipos de determinantes. Para lo que aquí queremos focalizar, lo que más interesa de las búsquedas es la presencia de los diferentes tipos de ocurrencias de "haber" con definido analizadas en las dos secciones anteriores y su relación con otros factores, como el campo discursivo y el género que conseguimos aislar a partir de los datos del corpus, que fue la "entrevista en medios de comunicación" en intersección con el campo político. Especialmente interesará la comparación entre la construcción que venimos focalizando, que, como explicamos, condensa modalidad con nominalización, y que presentamos con los ejemplos (11) a (14), y las demás que hemos presentado. Para facilitar la presentación de datos, en adelante denominaremos ese tipo de construcción como "modal + nomlz".

4 Para determinar la cantidad de casos sobre los cuales haremos comentarios cualitativos específicos, tenemos en cuenta las limitaciones de extensión del artículo. 
Un primer dato que nos llamó la atención, y que nos ayudó inclusive a profundizar las observaciones que sintetizamos en el apartado anterior, se registró en las búsquedas específicas por "hay el" y "hay la"5 en el Corpus del Español. Observando la clasificación de los casos que el sistema realiza, encontramos que 21 de los 100 casos de "hay la" están clasificados como "Entrevista” y corresponden a la trascripción de grabaciones de ese género en medios de comunicación, todas ellas con políticos de diferentes países hispanohablantes. Veinte de esos 21 casos de "hay la" $(95,24 \%)$ presentaron la construcción "modal + nomlz". En "hay el" encontramos 9 casos de "Entrevista" sobre un total de 55 ocurrencias. De los 9 casos, 6 (66,67\%) corresponden a "modal + nomlz". Tanto para esa búsqueda como para las otras que refreiremos, sólo consideramos en "modal + nomlz" los casos en que esa construcción no se sobrepone con otros factores presentados en las secciones anteriores, como valor cuantificador ("si hay la menor sospecha de que...", "hay la suficiente certeza de que...") o empleos de "mismo/-a" (hay el mismo riesgo de que...").

Algunos de los casos registrados fueron (los numeramos en el orden atribuido por el sistema en la lista de resultados en "hay la" o en "hay el"):

(75) Lo que sí puedo asegurar es que en todos los niveles del priísmo $^{6}$, hay la decisión de que nuestro candidato surja a través de un proceso ampliamente participativo.

(81) Hay la suposición de que hubo una acción fraudulenta.

(38) ¿Pero no hay el riesgo de que se diera una crisis porque ya tenemos seis meses de huelga?

(40) Hay el compromiso de avanzar.

Otros sustantivos que aparecieron en esas construcciones son posibilidad (6 veces en los 20 casos), intención (3 veces), decisión, suposición (2 veces), opción, impresión, determinación, sospecha, información, necesidad, temor, proyecto.

5 Para esta primera exploración, consideramos solamente los resultados para el presente del indicativo, en los dos corpora. La decisión se debió a que fue la única forma verbal con la cual obtuvimos resultados en cantidad suficiente para discriminar diversos tipos de construcción, con varios casos para cada tipo. Trabajamos solo con el singular para no tener que considerar, en esta primera reflexión, las especificidades del plural en cuanto al efecto de definitud. Las búsquedas fueron, entonces, siempre para "hay la" y "hay el".

6 Relativo al PRI, Partido Revolucionario Institucional (México). 
Esas ocurrencias nos mostraron una muy alta incidencia de la construcción "modal + nomlz" para el género entrevista en el discurso político. De los casos del Corpus del Español que no correspondían a ese género, sólo aparece en 16 entre los 79 del criterio "hay la" (20,25\%), y 6 de ellos corresponden a "Noticia" en la clasificación del sistema. Para "hay el", son 2 entre 46 (4,35\%). Resumiendo los índices:

Tabla 1 - Proporción de "modal + nomlz" en Corpus del Español, siglo XX

\begin{tabular}{|c|c|c|c|c|}
\hline \multirow{2}{*}{ Búsqueda } & \multicolumn{2}{|c|}{ Entrevista política } & \multicolumn{2}{c|}{ Otros dominios } \\
\cline { 2 - 5 } & Casos & $\%$ & Casos & $\%$ \\
\hline hay la & 20 de 21 & 95,24 & 16 de 79 & 20,25 \\
\hline hay el & 6 de 9 & 66,67 & 2 de 46 & 4,35 \\
\hline
\end{tabular}

En cuanto al CREA, las búsquedas se pueden realizar por lo que el sistema denomina "temas" y que corresponden, en algunos casos y de modo muy general, a tipos discursivos relacionados con prácticas sociales, como definimos antes a partir de Maingueneau (2008).

Realizamos nuestra búsqueda, primeramente, en el gran tema "Política, economía, comercio y finanzas", incluyendo todas sus subdivisiones. La búsqueda para "hay la" dio 91 ocurrencias, de las cuales 45 (49,45\%) correspondieron a "modal + nomlz". En "hay el" tuvimos 49 ocurrencias, 18 de ellas $(36,73 \%)$ para "modal + nomlz". La proporción para esa construcción que focalizamos fue notablemente mayor que en el gran tema "Artes", donde "modal + nomlz" arrojó 6 de 35 (17,64\%) para "hay la" y 3 de 19 (15,78\%) para "hay el". Y además de la tendencia que nos puede mostrar esa diferencia cuantitativa, la observación de los 9 casos particulares de "modal + nomlz" que aparecieron en "Artes" muestra que corresponden, de modo general, a fragmentos de confrontación polémica. Algunos, en textos ensayísticos, contraponiendo posturas en períodos o párrafos encabezados por adversativas, otros en discusiones en medios de comunicación sobre políticas culturales:

(19) Que se recorte en promoción del arte es malo, pero si hay la necesidad de hacerlo, no queda más remedio. 
(22) No hay filosofía ni teoría estética que valga; sólo hay la exigencia empresarial de que en el costoso lanzamiento de una firma no exista posibilidad de confusión.

Aún en el CREA, la consulta al gran tema "Ciencia y Tecnología” muestra resultados en todo análogos. La proporción para "modal + nomlz" es también mucho menor que en "Política...": 4 casos sobre 21 (19,04\%) en el femenino y 2 sobre $9(22,22 \%)$ en el masculino. Y de los 6 casos, 5 corresponden a problemáticas político-económicas. Tres de ellos, con el segmento "hay la necesidad", corresponden a fragmentos claramente argumentativos de un artículo sobre producción de algarrobos que discute cómo mejorar la competitividad en el mercado. Los otros dos no corresponden a la voz del locutor investigador sino que son discurso reportado de agentes participantes en algún tipo de situación económicamente conflictiva y también están bajo el alcance de marcadores evaluativos y/o de contraposición de perspectivas (destacado nuestro):

[4] Es normal que las ventas se desplomen en enero a consecuencia de la cuesta, pero entre los comerciantes hay la confianza de que el próximo mes aumentarán.

[3] Comentó que entre los productores hay el temor de que se haga realidad el proyecto de distribuir cerdos, como parte de los programas del gobierno, porque sería un duro golpe para los criadores.

Hecha la salvedad de la importancia que damos a la observación cualitativa que acabamos de mostrar, resumimos también los índices ya dados para el CREA.

\section{Tabla 2 - Proporción de "modal + nomlz" en el CREA}

\begin{tabular}{|c|c|c|c|c|c|c|}
\hline & \multicolumn{2}{|c|}{$\begin{array}{l}\text { Política, economía, } \\
\text { comercio y finanzas }\end{array}$} & \multicolumn{2}{|c|}{ Artes } & \multicolumn{2}{c|}{ Ciencia y tecnologia } \\
\cline { 2 - 7 } & Casos & $\%$ & Casos & $\%$ & Casos & $\%$ \\
\hline hay la & 45 de 91 & 49,45 & 6 de 35 & 17,64 & 4 de 21 & 19,04 \\
\hline hay el & 18 de 49 & 36,73 & 3 de 19 & 15,78 & 2 de 9 & 22,22 \\
\hline
\end{tabular}




\section{Conclusiones}

Las proporciones encontradas, pero sobre todo la observación cualitativa y analítica de los casos transversalmente a las clasificaciones propuestas en los instrumentos de búsqueda, señalan que la construcción presentativa definida que hemos delimitado y denominado "modal + nomlz" se relaciona fuertemente con secuencias textuales que abundan en contraposiciones polémicas. Se concentra más en los temas objeto de interés público conflictivo, y el hecho de que aparezca más cuando la forma genérica es una entrevista en los medios de comunicación se puede relacionar con el doble proceso de interlocución que en ellas, empíricamente, tiene lugar: con el público de destino y con el entrevistador, cuya intervención hace entrar en escena nuevas perspectivas.

Ya en la tradición bajtiniana se hallaba la propuesta de que la evolución de una forma en la lengua, como parte de un repertorio estilístico, se relaciona con su expresividad en determinados géneros (BAJTÍN, 1982, pp. 250-251), lo que podemos ampliar hacia otras unidades del discurso que permiten abordar analíticamente ese orden.

Creemos que en la base de la presencia de la presentativa definida "modal + nomlz" en esas secuencias y tipologías está el particular desplazamiento que esa construcción opera en las perspectivas de los participantes del cuadro enunciativo, combinado con la también singular articulación entre saberes y participantes dada por las marcas de modalidad y los rastros de nominalización. Así, vemos que resulta pertinente incorporar el funcionamiento de la enunciación y su complejidad en el camino de caracterizar las formas de la siempre "excepcional" concurrencia de presentativos y definitud.

\section{Referencias}

APOTHÉLOZ, Denise. Papel e funcionamento da anáfora na dinâmica textual. In: CAVALCANTE, Mônica, RODRIGUES, Bernardette y CIULLA, Alena. Referenciação. São Paulo: Contexto, 2003, pp. 53-84.

BAJTÍN, Mijaíl. Estética de la creación verbal. México: Siglo XXI, 1982.

BORGES, Jorge Luis ([1960] 2004). El cautivo. In: Obras completas, v. 2. Buenos Aires: Emecé, p. 166. 
DUCROT, Oswald. La argumentación de autoridad. [1981] In: El decir y lo dicho. Buenos Aires: Edicial, 2001a, pp. 149-165.

. La noción de sujeto hablante. [1982] In: El decir y lo dicho. Buenos Aires: Edicial, 2001b, pp. 251-277.

FERNÁNDEZ RAMÍREZ, Salvador. Gramática española. Vol. 4. El verbo y la oración. Edición completada y preparada por Ignacio Bosque. Madrid: Arco Libros, 1987.

FLINICH, María I. Enunciación. Buenos Aires: Eudeba, 2012.

HALlIDAY, M. y HASAN, R. Cohesion in English. New York: Routledge, [1976] 2013.

KLEIBER, Georges. Article défini, théorie de la localisation et présupposition existentielle. Langue Française, 57: 87-105.

LEONETTI, Manuel. Los determinantes. Madrid: Arco Libros, 1999a.

. El artículo. In: BOSQUE, I., e DEMONTE, V.: Gramática descriptiva de la lengua española. Madrid: Espasa, pp. 787-890, $1999 \mathrm{~b}$.

LYONS, Christopher. Definiteness. Cambridge: Cambridge University Press, 1999.

MAINGUENEAU, Dominique. Cenas da enunciação. São Paulo: Parábola, 2008.

NEVES, María Helena M. (1999). Gramática de usos do português. São Paulo: Ed. UNESP.

RAE - REAL ACADEMIA ESPAÑOLA. Nueva gramática de la lengua española. 3 vol. Madrid: Espasa, 2009.

ZOPPI FONTANA, M. (2004). A arte de cair fora. O lugar do terceiro na enunciação. Ecos, 2: 59-69.

Corpora citados (según indicaciones para cita dadas en cada uno):

DAVIES, Mark. (2002) Corpus del Español: 100 millionwords, 1200s-1900s. Disponible online en http://www.corpusdelespanol.org.

REAL ACADEMIA ESPAÑOLA: Banco de datos (CREA) [en línea]. Corpus de referencia del español actual. <http://www.rae.es> [consultas en noviembre y diciembre de 2013] 


\title{
DO FÓRICO ÀS PERSPECTIVAS NA ENUNCIAÇÃO. ANÁLISE DE CONSTRUÇÓES APRESENTACIONAIS DEFINIDAS EM ESPANHOL
}

\begin{abstract}
RESUMO
Este artigo trata sobre a ocorrência, em espanhol, do verbo "haber" com artigo definido, revisando algumas interpretaçōes à luz de teorizaçôes sobre a enunciação que questionam a unicidade do sujeito falante. A consideração das perspectivas e vozes na enunciação conduz ao enfoque de um tipo específico dentro das construções apresentacionais definidas, sobre o qual se informam buscas em corpora e conclusóes acerca do seu potencial no funcionamento argumentativo.
\end{abstract}

PALAVRAS-CHAVE: construçôes apresentacionais; perspectiva na enunciação; artigo definido.

Recebido em 22/04/14 Aprovado em 29/05/14 